\title{
Características físico-químicas do leite cru refrigerado entregue em uma cooperativa no estado do Rio de Janeiro
}

\section{Physical-chemistries characteristics of refrigerated raw milk from a cooperative in Rio de Janeiro}

\author{
Maitê Figueiredo Freire, ${ }^{*}$ Marco Antonio Sloboda Cortez, ${ }^{* *}$ Adriana Cristina de Oliveira Silva, ${ }^{* *},{ }^{* *}$ Andrea Matta Ristow, ${ }^{* * *}$ \\ Maria Carmela Kasnowski, ${ }^{* * *}$ Neila Mello dos Santos Cortez ${ }^{* * *}$
}

\begin{abstract}
Resumo
Objetivou-se avaliar características físico-químicas como temperatura de chegada ao estabelecimento, alizarol, acidez, densidade relativa, gordura e índice crioscópico e assim diagnosticar possíveis pontos de estrangulamento da qualidade do leite. Foram colhidas 55 amostras de leite cru refrigerado entregue em uma Cooperativa de leite no Rio de Janeiro. As amostras foram analisadas no laboratório da Cooperativa e os dados obtidos foram comparados com os limites estabelecidos no Brasil. Os resultados demonstraram que a média da temperatura do leite recebido foi de $9,44^{\circ} \mathrm{C}$. Dezoito por cento das amostras apresentaram-se fora dos padrões de temperatura e 15\% apresentaram-se fora dos padrões de estabilidade ao alizarol a $78 \%$. A média encontrada na prova de acidez titulável foi de 15,44 ${ }^{\circ} \mathrm{D}$. Em relação às análises de densidade e gordura, todas se apresentaram dentro dos padrões de conformidade. Para o índice crioscópico, apenas duas apresentaram-se não conforme. Observou-se a necessidade de melhorar os cuidados com a obtenção e transporte de leite desta cooperativa. Para isso ações educacionais e a atuação mais efetiva dos serviços de inspeção são importantes ferramentas que podem ser utilizadas como uma forma de auxiliar a melhora das condições produtivas e influenciar positivamente a qualidade do leite produzido e consumido no Brasil.
\end{abstract}

Palavras-chave: leite, análises físico químicas, qualidade.

\begin{abstract}
The objective of this study was to evaluate milk physical and chemical characteristics, such temperature, alizarol, acidity, relative density, fat content and milk cryoscopy; and when identify possible problems to milk quality. It is fundamental the attendance of requirements established in the regulations in order to guarantee the safety of animal products. To this, 55 samples of refrigerated raw milk were collected from a dairy coopeartive in Rio de Janeiro and then analyzed. The obtained data were compared to legal limits in Brazil. Temperature average was $9,44^{\circ} \mathrm{C}$. Eighteen percent of samples were out of temperature and fifteen were out of alizarol patterns. To acidity the average was $15,44^{\circ} \mathrm{D}$. In relation to density analyses and fat content, all were inside the conformity patterns. Two samples were out of limits to milk crioscopy. Then it is necessary to improve milk production and caption. For that, educational approaches and inspection service actions are important tools that should be used to improve conditions and to influence positively the milk quality in Brazil.
\end{abstract}

Keywords: milk, physical-chemistry analysis, quality.

\section{Introdução}

Em relação ao método de produção de leite usualmente utilizado no estado do Rio de Janeiro, a ordenha é basicamente manual e a mão-de-obra não é especializada, o que conseqüentemente gera baixos níveis de produção leiteira e baixa qualidade microbiológica (FAERJ/SEBRAE, 2003). Estes fatores proporcionam motivos para que o leite e derivados produzidos no Brasil sejam impedidos de serem exportados devido a barreiras sanitárias aplicadas por outros países. A composição do leite é um dos critérios mais avaliados na definição da qualidade do produto, principalmente em relação à concentração de gordura e de proteína. Tais parâmetros, assim como os parâmetros relacionados com a qualidade microbiológica são utilizados como critério mínimo para aceitação da matéria-prima por

* Discente - Medicina Veterinária da Faculdade de Veterinária - Universidade Castelo Branco.

** Departamento de Tecnologia dos Alimentos, Faculdade de Veterinária - Universidade Federal Fluminense. Rua Vital Brazil Filho, 64. Niterói/ RJ. 24.230-340.

*** Programa de Pós-Graduação em Medicina Veterinária - Higiene Veterinária e Processamento Tecnológico de Produtos de Origem Animal da Faculdade de Veterinária - Universidade Federal Fluminense.

Autor para correspondência. Marco Antonio Sloboda Cortez. E-mail: macortez@vm.uff.br. 
parte da indústria. Estes incluem contagem de bactérias heterotróficas aeróbias mesófilas, contagem de células somáticas, alizarol, redutase, álcool, acidez, lacto-filtração e temperatura.

No trabalho realizado por Roos et al. (2002), foi determinada a temperatura do leite de 18.587 tanques isotérmicos na chegada do caminhão à indústria, de janeiro a dezembro de 1998. Os resultados foram confrontados com a Instrução Normativa no 51 (Brasil, 2002), que estabelece a temperatura máxima permitida para chegada do leite na indústria como $10^{\circ} \mathrm{C}$. Do total de tanques, somente $12.491(67,20 \%)$ apresentaram temperatura de acordo com a legislação, pela média dos meses de janeiro a dezembro. O percentual de tanques com temperatura superior à exigida foi maior durante os meses de verão, particularmente janeiro $(51,24 \%)$ e fevereiro (55,92\%), quando a temperatura ambiental é elevada. Com isso, concluiu a necessidade de maior controle da refrigeração do leite desde o momento de sua obtenção, até a chegada na indústria. Recomenda-se que a temperatura de armazenamento seja de $4^{\circ} \mathrm{C}$, podendo chegar ao máximo até $7^{\circ} \mathrm{C}$, dentro de duas horas após o término da ordenha, e menor que $10^{\circ} \mathrm{C}$, durante a adição de leite da ordenha consecutiva. Todo o sistema de frio deve ser adequadamente dimensionado e mantido, além de estar em perfeito funcionamento (Dias, 2000).

O teste do alizarol baseia-se na ocorrência de coagulação por efeito da elevada acidez ou do desequilíbrio salino, quando se promove desestabilização das micelas pelo álcool e na mudança de colocação da mistura pela alizarina, como indicador de $\mathrm{pH}$, auxiliando a diferenciação entre o desequilíbrio salino e a acidez excessiva (Brasil, 1981). O teste do alizarol pode apresentar resultados alterados nas seguintes condições: elevada acidez do leite; índice de mastite do rebanho elevada; vacas próximas da secagem ou recémparidas e desequilíbrio salino (excesso de cálcio e magnésio em relação a fosfato e citrato) (Brito, 2005). O leite que coagula nessa prova não resiste ao calor, portanto, não pode ser misturado aos demais. Desta forma, o leite ácido não resistiria aos tratamentos térmicos utilizados geralmente pelas indústrias, sendo então uma importante característica a ser controlada.

A determinação da acidez titulável consiste na titulação de determinado volume de leite por uma solução alcalina de concentração conhecida, utilizando como indicador a fenolftaleína (Brasil, 1981). As bactérias láticas são geralmente os responsáveis pela acidificação, devida à transformação da lactose em ácido lático. Se o fenômeno é espontâneo se deve principalmente ao Streptococcus lactis, que se desenvolve perfeitamente à temperatura ambiente. Quando a acidez alcança $35^{\circ}-40^{\circ} \mathrm{D}$, a caseína flocula ao submeter o leite em ebulição. Na faixa de $60^{\circ}$ a $70^{\circ} \mathrm{D}$, o fenômeno ocorre em temperatura ambiente. Além das bactérias lácticas, há outros grupos de bactérias que podem produzir a acidificação do leite, tais como coliformes, enterococos, estafilococos, micrococos, etc. (Veisseyre, 1980). Ao ser ordenhado, o leite não apresenta nenhuma fermentação, pois, sua acidez natural é decorrente dos componentes presentes no próprio leite: caseína $\left(6^{\circ} \mathrm{D}\right)$; fosfatos $\left(6^{\circ} \mathrm{D}\right) ; \mathrm{CO}_{2}\left(1-2^{\circ} \mathrm{D}\right)$; albumina $\left(1^{\circ} \mathrm{D}\right)$; citrato $\left(1^{\circ} \mathrm{D}\right)$. Depois de algum tempo, com a ação da temperatura e com a perda dos inibidores naturais, o leite passa a apresentar elevação da acidez devido à acidificação da lactose, em decorrência do metabolismo de microrganismos presentes. Portanto, é atribuída à acidez a perda do leite pelo produtor nas usinas, quando a acidificação produzida ultrapassa a 1,8 grama por litro de leite, que é igual $18^{\circ} \mathrm{D}(18$ graus Dornic). O Regulamento Técnico de Identidade e Qualidade de Leite Cru Refrigerado cita que o limite de acidez titulável g/ácido láctico/100 mL deve estar entre 0,14-0,18 (Brasil, 2002).

$\mathrm{O}$ medição da densidade relativa a $15^{\circ} \mathrm{C}$ consiste na imersão de um densímetro de massa constante no líquido que provocará deslocamento de uma quantidade deste, que será, em massa, igual à do densímetro utilizado e, em volume, proporcional à densidade da amostra. Esse deslocamento fará o líquido alcançar um valor na escala graduada em graus densitométricos (Brasil, 1981). A densidade pode ser mensurada através de densímetros ou aerômetros que consiste no método mais rápido e prático de se determinar a densidade relativa de diferentes soluções, apresentando resultados bastante exatos. Este equipamento apresenta escala apropriada para a leitura da densidade de cada material específico a ser testado. Quando o destino é a análise de leite recebe o nome de lactodensímetro. Se apresentar um termômetro acrescido ao equipamento, é designado como termolactodensímetro. São vários os modelos existentes, mas o densímetro de Quevenne é o mais comum.

A densidade é uma propriedade física dos corpos e, dependendo da natureza, da quantidade e do estado de dissolução coloidal ou verdadeira das partículas, apresentará oscilação em seus valores. Para o leite, a densidade é considerada como uma propriedade aditiva, dependendo diretamente da matéria dissolvida e suspensa no volume pesquisado. Na realidade, a densidade do leite consiste da soma das densidades do extrato seco desengordurado, gordura e água. Segundo o Regulamento da Inspeção Industrial e Sanitária de Produtos de Origem Animal (Brasil, 1997), o leite normal apresenta densidade variando entre 1,028 a $1,033 \mathrm{~g} / \mathrm{mL}$, medida a $15^{\circ} \mathrm{C}$. Porém, segundo os Regulamentos Técnicos de Produção, Identidade, Qualidade, Coleta e Transporte de Leite (Instrução Normativa nํ 51) para Leite tipo $\mathrm{A}$, tipo $\mathrm{B}$, tipo $\mathrm{C}$ e leite cru refrigerado, os valores normais de densidade variam entre 1,028 a $1,034 \mathrm{~g} / \mathrm{mL}$. (Brasil, 2002). Além disso, segundo a legislação brasileira, a densidade do leite deverá sempre ser expressa a $15^{\circ} \mathrm{C}$, sendo que, caso não seja medida com o leite nessa temperatura, correções deverão ser feitas nos valores lidos, ajustando-os às Normas (o MAPA não recomenda a correção em amostras com temperaturas inferiores a $10^{\circ} \mathrm{C}$ ou superiores a $20^{\circ} \mathrm{C}$ ). $\mathrm{O}$ valor da densidade estará aumentado se a temperatura da amostra estiver mais baixa, o inverso sendo também verdadeiro. A temperatura irá interferir no estado físico do leite, promovendo, por exemplo, a contração dos constituintes sólidos sob o frio, o que leva à redução do volume ocupado pelos mesmos e conseqüentemente, ao aumento da densidade final do leite. A maior densidade do leite é obtida a $0,3^{\circ} \mathrm{C}$, sujeita a variações em função da composição. Uma correção aproximada de 0,0002 por grau centígrado, aditiva para temperaturas superiores a $15^{\circ} \mathrm{C}$ e subtrativa para as inferiores a $15^{\circ} \mathrm{C}$, pode ser aplicada para a correção dos valores (Penna et al., 2001).

A amostra fraudada com água terá densidade menor do que a amostra normal. Como a densidade da água é estabelecida 
como 1,0, o resultado final no leite tende a se aproximar desse valor. Uma das aplicações práticas da determinação da densidade é justamente a pesquisa de fraude por adição de água ou desnate na propriedade.

A determinação da gordura no leite baseia-se no ataque seletivo da matéria orgânica por meio de ácido sulfúrico, com exceção da gordura que será separada por centrifugação, auxiliada pelo álcool amílico que modifica a tensão superficial (Brasil, 1981). A gordura representa um dos macrocomponentes do leite, com valores médios de 3,9\% e está diretamente ligada a diversas características físico-químicas e sensoriais do leite e dos seus derivados. Assim, a determinação da porcentagem de gordura pode auxiliar na interpretação de algumas dessas características. No entanto, dentre os componentes do leite, a gordura é o mais variável e geralmente o primeiro a sofrer alterações diante de qualquer fator de origem genética, ambiental e fisiológica que esteja afetando o metabolismo normal da vaca (Valsechi, 2001). O Regulamento Técnico de Identidade e Qualidade de Leite Cru Refrigerado cita que o limite de teor original da matéria gorda $\mathrm{g} / 100 \mathrm{~g}$ é de no mínimo 3,0g (Brasil, 2002).

O princípio da medição do índice crioscópico baseia-se no super-congelamento de uma amostra de leite a uma temperatura apropriada e aplicação de uma agitação mecânica, o que ocasiona um rápido aumento da temperatura até um patamar o qual corresponde ao ponto de congelamento da amostra (Brasil, 1981). A crioscopia do leite corresponde à medição do ponto de congelamento ou da depressão do ponto de congelamento do leite em relação ao da água. A composição normal do leite gera um valor aproximado de $-0,531^{\circ} \mathrm{C}\left(-0,550^{\circ} \mathrm{H}\right)$ para o ponto crioscópico. Este valor depende de uma série de fatores relacionados com o animal, o leite, o ambiente, o processamento e as técnicas crioscópicas, ocasionando dificuldades para o estabelecimento de padrões crioscópicos. A leitura pode ser realizada em duas unidades: graus Celsius $\left({ }^{\circ} \mathrm{C}\right)$ ou graus Hortvest $\left({ }^{\circ} \mathrm{H}\right)$, dependendo de ajustes do equipamento (Fonseca et al., 1993). Uma das principais falsificações do leite é a aguagem, sendo muito freqüente (Sá, 2004). Além de diminuir o valor nutritivo do produto, pode ser fonte de contaminação por perigosos germes patogênicos (Veisseyre, 1980). Essa aguagem irá fazer com que o leite congele mais rapidamente, ficando com um ponto de congelamento mais próximo da água. Pela Instrução Normativa no 51 , o limite do índice crioscópico é a $-0,530^{\circ} \mathrm{H}$ (equivalente a $-0,512^{\circ} \mathrm{C}$ ) (Brasil, 2002).

Portanto, pode-se observar que a qualidade do leite é muito importante para as indústrias e produtores, tendo em vista a influência nos hábitos de consumo e na produção de derivados. Para a indústria, a qualidade da matéria-prima está diretamente relacionada com as características do produto final, que irá apresentar melhores características físicoquímicas, microbiológicas e sensoriais. Para o produtor, essa referência vai implicar melhor remuneração e maior procura ao seu produto, por refletir a boa sanidade do rebanho. Atingindo o consumidor final, a salubridade do leite gera uma maior segurança do consumo do produto in natura, assim como dos derivados lácteos. Buscando uma alimentação mais saudável, cada vez mais os consumidores procuram informações sobre o que consomem. Desta forma, exigem melhor qualidade dos produtos disponíveis e fiscalizam a adequação dos produtos às informações indicadas nos rótulos ou veiculadas em meios de comunicação. Para que este objetivo seja alcançado, é muito importante a aprovação e exigência legal de padrões físico-químicos e microbiológicos mais adequados. A entrada em vigor da Instrução Normativa no 51 de 2002 (Brasil, 2002), que determina níveis aceitáveis de qualidade e normalidade do leite cru refrigerado, demonstra o esforço do Governo e das Empresas na melhora da qualidade do leite obtido no Brasil. Portanto, o objetivo deste estudo foi verificar por meio de análises físico-químicas, se o leite cru refrigerado recebido em uma cooperativa no estado do Rio de Janeiro está em conformidade com os novos padrões de qualidade exigidos pela Legislação (Brasil, 2002), possibilitando traçar um pequeno perfil regional da produção de leite e diagnosticar possíveis pontos de estrangulamento da qualidade deste produto.

\section{Materiais e métodos}

Este estudo foi realizado em uma Cooperativa do estado do Rio de Janeiro, durante o mês de dezembro de 2002. Neste período, 55 amostras de leite cru refrigerado foram analisadas quanto às características físico-químicas: temperatura, alizarol, acidez, densidade, gordura e índice crioscópico. Todas as técnicas analíticas seguiram procedimentos descritos no manual do LANARA (Brasil, 1981). Os dados obtidos foram analisados estatisticamente utilizando-se o Programa Microsoft Excel (média e desvio-padrão). Para determinar a homogeneidade entre os conjuntos de dados foi calculado o coeficiente de variação (CV), a partir da seguinte equação: CV = desvio padrão/ média.

\section{Resultados e discussão}

Os resultados das análises realizadas no leite recebido em uma cooperativa de leite do estado do Rio de Janeiro durante o mês de dezembro de 2002 podem ser observados na Tabela 1 .

Todas as 55 amostras de leite cru resfriado foram analisadas quanto à temperatura de recebimento, sendo que dez (aproximadamente 18\%) delas apresentaram temperatura não conforme com o recomendado pela Instrução Normativa no 51 (Brasil, 2002) por apresentaram temperatura acima dos $10^{\circ} \mathrm{C}$. A média de temperatura encontrada foi de $9,44^{\circ} \mathrm{C}$, com um coeficiente de variação relativamente baixo (Tabela 1).

Mesmo a média estando dentro do permitido pela legislação, foram observados alguns valores maiores que o padrão (acima de $10^{\circ} \mathrm{C}$ ), podendo-se identificar problemas em relação à conservação do leite nestes estabelecimentos específicos, como um indicativo de má conservação do leite fluido após a ordenha. Por se tratar de um alimento tão perecível deve ser mantido em temperaturas baixas e controladas para melhor garantia de qualidade e segurança do produto final.

No teste do alizarol, das 55 amostras analisadas, oito (15\%) apresentaram-se instáveis ao alizarol a $78 \%(\mathrm{v} / \mathrm{v})$, ou seja, sofreram coagulação durante a execução do teste (Tabela 1). Estas mesmas amostras tiveram níveis de acidez no seu limite máximo (uma com 0,17 e sete com $0,18 \mathrm{~g}$ de acido lático/ $100 \mathrm{~mL}$ ). A taxa de conformidade foi de $85 \%$. 
Tabela 1: Valores das análises físico-químicas de leite cru refrigerado entregue em uma cooperativa de leite no estado do Rio de Janeiro durante o mês de dezembro de 2002

\begin{tabular}{|c|c|c|c|c|c|c|}
\hline Amostras & $\begin{array}{c}\text { Temperatura } \\
\left({ }^{\circ} \mathrm{C}\right)\end{array}$ & $\begin{array}{c}\text { Alizarol } \\
(78 \%)\end{array}$ & $\begin{array}{c}\text { Acidez } \\
\left({ }^{\circ} \mathrm{D}\right) \\
\end{array}$ & $\begin{array}{c}\text { Densidade } \\
(\mathrm{mg} / \mathrm{L})\end{array}$ & $\begin{array}{c}\text { Gordura } \\
(\mathrm{g} / 100 \mathrm{~mL})\end{array}$ & $\begin{array}{c}\text { Índice } \\
\text { crioscópico }\left({ }^{\circ} \mathrm{C}\right) \\
\end{array}$ \\
\hline 1 & 8,7 & Conforme & 15,0 & 1032,2 & 3,5 & $-0,543$ \\
\hline 2 & 9,2 & Conforme & 15,0 & 1032,4 & 3,5 & $-0,540$ \\
\hline 3 & 10,0 & Conforme & 15,0 & 1028,0 & 3,5 & $-0,465^{\star *}$ \\
\hline 4 & 10,0 & Conforme & 15,0 & 1032,0 & 3,5 & $-0,537$ \\
\hline 5 & 13,0 & Não conforme & $18,0^{*}$ & ND & ND & ND \\
\hline 6 & 11,0 & Não conforme & $18,0^{*}$ & ND & 3,6 & ND \\
\hline 7 & 10,9 & Conforme & 15,0 & 1032,4 & 3,5 & $-0,542$ \\
\hline 8 & 8,8 & Conforme & 15,0 & 1032,4 & 3,5 & $-0,538$ \\
\hline 9 & 8,0 & Conforme & 15,0 & 1032,2 & 3,5 & $-0,544$ \\
\hline 10 & 8,0 & Conforme & $18,0^{*}$ & 1032,6 & 3,5 & $-0,548$ \\
\hline 11 & 9,0 & Não conforme & $18,0^{*}$ & ND & 3,5 & ND \\
\hline 12 & 9,0 & Não conforme & $18,0^{*}$ & ND & 3,5 & ND \\
\hline 13 & 10,6 & Conforme & 15,0 & 1032,0 & 3,6 & $-0,538$ \\
\hline 14 & 8,9 & Conforme & 15,0 & 1032,0 & 3,6 & $-0,537$ \\
\hline 15 & 12,0 & Conforme & 15,0 & 1032,2 & 3,6 & $-0,536$ \\
\hline 16 & 10,0 & Conforme & 15,0 & 1032,0 & 3,5 & $-0,536$ \\
\hline 17 & 9,5 & Conforme & 15,0 & 1032,4 & 3,5 & $-0,538$ \\
\hline 18 & 9,8 & Conforme & 15,0 & 1032,6 & 3,6 & $-0,544$ \\
\hline 19 & 8,5 & Conforme & 15,0 & 1032,4 & 3,6 & $-0,541$ \\
\hline 20 & 10,0 & Conforme & 15,0 & 1032,0 & 3,7 & $-0,539$ \\
\hline 21 & 10,0 & Conforme & 16,0 & 1032,0 & 3,6 & $-0,543$ \\
\hline 22 & 10,0 & Não conforme & $18,0^{*}$ & 1032,0 & 3,6 & ND \\
\hline 23 & 8,0 & Não conforme & $18,0^{*}$ & 1032,0 & 3,6 & ND \\
\hline 24 & 9,0 & Conforme & 15,0 & 1032,4 & 3,6 & $-0,540$ \\
\hline 25 & 11,0 & Conforme & 15,0 & 1032,0 & 3,5 & $-0,535$ \\
\hline 26 & 10,0 & Conforme & 15,0 & 1032,2 & 3,5 & $-0,542$ \\
\hline 27 & 8,8 & Conforme & 15,0 & 1032,6 & 3,5 & $-0,544$ \\
\hline 28 & 9,0 & Não conforme & $17,0^{*}$ & ND & ND & ND \\
\hline 29 & 8,0 & Não conforme & $18,0^{*}$ & 1032,2 & 3,6 & $-0,539$ \\
\hline 30 & 10,0 & Conforme & 15,0 & 1032,0 & 3,6 & $-0,545$ \\
\hline 31 & 8,9 & Conforme & 15,0 & 1032,4 & 3,5 & $-0,543$ \\
\hline 32 & 10,0 & Conforme & 15,0 & 1032,6 & 3,5 & $-0,541$ \\
\hline 33 & 11,0 & Conforme & 15,0 & 1028,6 & 3,5 & $-0,480^{\star *}$ \\
\hline 34 & 13,0 & Conforme & 15,0 & 1031,8 & 3,6 & $-0,534$ \\
\hline 35 & 8,0 & Conforme & 14,0 & 1032,0 & 3,7 & $-0,535$ \\
\hline 36 & 8,5 & Conforme & 14,0 & 1032,3 & 3,7 & $-0,541$ \\
\hline 37 & 12,0 & Conforme & 15,0 & 1032,0 & 3,8 & $-0,539$ \\
\hline 38 & 15,0 & Conforme & 15,0 & 1031,0 & 3,8 & $-0,541$ \\
\hline 39 & 5,0 & Conforme & 15,0 & 1032,6 & 3,6 & $-0,540$ \\
\hline 40 & 7,0 & Conforme & 15,0 & 1032,4 & 3,6 & $-0,542$ \\
\hline 41 & 8,9 & Conforme & 15,0 & 1032,2 & 3,6 & $-0,538$ \\
\hline 42 & 7,5 & Conforme & 15,0 & 1032,0 & 3,6 & $-0,547$ \\
\hline 43 & 9,1 & Conforme & 15,0 & 1032,2 & 3,5 & $-0,520$ \\
\hline 44 & 8,6 & Conforme & 15,0 & 1032,0 & 3,8 & $-0,539$ \\
\hline 45 & 7,8 & Conforme & 14,0 & 1031,8 & 4,0 & $-0,536$ \\
\hline 46 & 8,2 & Conforme & 15,0 & 1032,4 & 3,6 & $-0,547$ \\
\hline 47 & 10,0 & Conforme & 15,0 & 1032,6 & 3,6 & $-0,541$ \\
\hline 48 & 10,0 & Conforme & 15,0 & 1032,8 & 3,5 & $-0,535$ \\
\hline 49 & 7,9 & Conforme & 15,0 & 1032,6 & 3,5 & $-0,539$ \\
\hline 50 & 8,5 & Conforme & 15,0 & 1032,0 & 3,6 & $-0,543$ \\
\hline 51 & 8,9 & Conforme & 15,0 & 1032,4 & 3,6 & $-0,538$ \\
\hline 52 & 9,5 & Conforme & 15,0 & 1032,6 & 3,7 & $-0,542$ \\
\hline 53 & 7,0 & Conforme & 15,0 & 1032,4 & 3,7 & $-0,539$ \\
\hline 54 & 10,0 & Conforme & 15,0 & 1032,0 & 3,5 & $-0,545$ \\
\hline 55 & 10,0 & Conforme & 15,0 & 1032,0 & 3,6 & $-0,544$ \\
\hline \multirow{3}{*}{$\begin{array}{c}\text { Média } \\
\text { Desvio-padrão } \\
\text { Coeficiente de } \\
\text { Variação (\%) }\end{array}$} & 9,44 & - & 15,44 & 1032,06 & 3,59 & $-0,537$ \\
\hline & 1,63 & - & 1,13 & 0,83 & 0,10 & 0,014 \\
\hline & 0,173 & - & 0,074 & 0,001 & 0,028 & 0,027 \\
\hline
\end{tabular}

* Leite ácido: fins industriais; ${ }^{* *}$ Leite alterado: fins industriais; ND: Não Determinado 
$\mathrm{Na}$ determinação da acidez titulável, as 55 amostras (100\%) estavam dentro dos valores permitidos pela legislação (Brasil, 2002). A média encontrada foi de $15,4^{\circ} \mathrm{D}$ e o coeficiente de variação 0,0735 , mostrando que houve pouca variação entre os valores encontrados. A proximidade do limite máximo permitido $\left(18,0^{\circ} \mathrm{D}\right)$ de oito amostras parece ter relação com as temperaturas de transporte, uma vez que em temperaturas mais elevadas, as bactérias intensificam a multiplicação e 0 metabolismo atuando na composição do leite, como na degradação da lactose gerando ácido lático.

Em relação à densidade, cinco amostras, devido ao seu desvio para fins industriais por estarem fora dos padrões para o teste do alizarol, sendo que das 50 amostras restantes, todas $(100 \%)$ apresentaram-se em conformidade com a legislação (Brasil, 2002), que é de 1028,0 a 1034,0mg/L. A média encontrada foi de $1032,06 \mathrm{mg} / \mathrm{L}$ e o coeficiente de variação bem baixo, mostrando que não houve muita variação dos valores da densidade do leite neste experimento (Tabela 1).

Das 55 amostras analisadas, apenas duas não tiveram o índice de gordura analisado, devido à não-utilização destes leites pela indústria. Das 53 analisadas, 100\% das amostras apresentaram valores dentro do estabelecido pela Instrução Normativa número 51 , que é de $3,0 \mathrm{~g} / 100 \mathrm{ml}$. Sendo que a média encontrada foi de $3,59 \mathrm{~g} / 100 \mathrm{ml}$ (Tabela 1 ).

Das 48 amostras analisadas, apenas duas (aproximadamente 4,0\%) tiveram o índice crioscópico fora dos padrões de conformidade, o que sugere a ocorrência de fraude por aguagem, já que os níveis encontrados estavam mais próximos ao ponto de congelamento da água. Sete amostras

\section{Referências}

AMIOT, J. Ciencia y Tecnología de la leche. Zaragoza: Acribia, 1991. BRASIL. Ministério da Agricultura. Secretaria Nacional de Defesa Agropecuária. Laboratório Nacional de Referência Animal. Métodos analíticos oficiais para controle de produtos de origem animal e seus ingredientes: métodos físicos e químicos. Brasília, DF, v. II, cap. 14, p. 1, 2, 4 e 5, 1981.

BRASIL. Ministério da Agricultura da Pecuária e Abastecimento. Regulamento da Inspeção Industrial e Sanitária de Produtos de Origem Animal. Inspeção Industrial e Sanitária do Leite e Derivados, cap. I, art. 475, 1997.

BRASIL. Ministério da Agricultura da Pecuária e Abastecimento. Secretaria Nacional de Defesa Agropecuária. Regulamentos Técnicos de Produção, Identidade e Qualidade do Leite tipo A, do Leite tipo B, do Leite tipo C, do Leite Pasteurizado e do Leite Cru Refrigerado e o Regulamento Técnico da Coleta de Leite Cru Refrigerado e seu Transporte a Granel, em conformidade com os Anexos a esta Instrução Normativa. Instrução Normativa ํㅡ 51 de 18 de setembro de 2002. Diário Oficial da República Federativa do Brasil. Publicado em 20/09/2002. Seção 1, página 13. Brasília, DF.

BRITO, M.A.P. É preciso primeiro saber por que o leite está dando positivo no teste do alizarol. Revista Balde Branco. Disponível em: <http://www.cnpgl.embr apa.br/jornaleite/carta.php? pagina=8>. Atualizado em 2006. não foram analisadas, devido à não-conformidade ao teste de alizarol. As demais amostras (41) apresentaram conforme o padrão definido de índice crioscópico estabelecido pela Instrução Normativa no 51 (Brasil, 2002), que é de $-0,512^{\circ} \mathrm{C}$. A média encontrada foi de $-0,537^{\circ} \mathrm{C}$ (Tabela 1$)$.

\section{Conclusão}

Parte do leite recebido encontrava-se fora dos padrões previstos pela legislação. Pode-se verificar que um dos principais problemas estava associado à temperatura de chegada do leite ao estabelecimento beneficiador. Este fator é de grande importância para a qualidade da matéria-prima e, conseqüentemente, para o produto final, uma vez que o aumento da temperatura está diretamente relacionado com a multiplicação bacteriana e posteriores alterações sensoriais e físico-químicas. Outro problema detectado foi em relação à adição de água ao leite. Além de ser uma fraude passível de punição, não há como garantir a qualidade da água utilizada nesta adição, que pode veicular microrganismos deteriorantes e patogênicos. Há muitos aspectos que devem ser empregados para melhorar a qualidade do leite produzido, tais como campanhas educacionais, profissionais capacitados, recursos financeiros, incentivos aos pequenos produtores rurais e para as cooperativas. Ações educacionais e um comprometimento mais efetivo dos serviços de inspeção também são importantes ferramentas a serem utilizadas como uma forma de auxiliar a melhora das condições produtivas e influenciar positivamente a qualidade do leite produzido e consumido no Brasil.

DIAS, A. F. Influência da temperatura na multiplicação das bactérias. Jornal da Produção de Leite- PDPL / RV. Ano XII, n. 136, jun. Viçosa - Minas Gerais, 2000.

FAERJ/SEBRAE - RIO DE JANEIRO. Diagnóstico da cadeia produtiva do leite do estado do Rio de Janeiro. Relatório de pesquisa, p. 262, 2003.

PENNA, C. F. de A. M.; SOUZA, M. R.;FONSECA, L. M.; CERQUEIRA, M. O. P.; LEITE, M. de O.; RODRIGUES, R. Determinação da densidade do leite. Universidade Federal de Minas gerais. Escola de Veterinária Departamento de Tecnologia e Inspeção de Produtos de Origem Animal. Belo Horizonte-2001.

ROOS, T. B.; OLIVEIRA, D. S.; MORAES, C. M.; GONZALEZ, H. L.; ALEXIS, M. A.; PORTO, C. R.; TIMM, C. D. Temperatura do leite cru entregue na indústria na Região Sudeste do Rio Grande do Sul. XXIX Congresso Brasileiro de Medicina Veterinária, p. 126, Gramado, 2002. SÁ, de E. Análises para detectar fraudes em leite. Revista Leite \& Derivados., n. 78, 2004.

VALSECHI, O. A. Tecnologia de Produtos Agrícolas de Origem Animal: o leite e seus derivados. Universidade Federal de São Carlos - Centro de Ciências Agrárias. Araras, SP, 2001.

VEISSEYRE, R. Lactología Técnica - Composición, recogida, tratamiento y transformación de la leche. Zaragoza: Acribia, p. 75-80. 1980. 